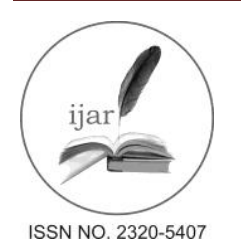

\author{
Journal homepage:http://www.journalijar.com \\ Journal DOI:10.21474/IJAR01
}

INTERNATIONAL JOURNAL

OF ADVANCED RESEARCH

RESEARCH ARTICLE

\title{
ULTRASONIC WAVES ASSISTED SYNTHESIS OF IRON AND ANTIBACTERIAL SILVER NANO PARTICLES.
}

\author{
S.Kothai ${ }^{{ }^{*}}$ and B.Jayanthi ${ }^{2}$. \\ 1. Associate Professor,Department of Chemistry, The Ethiraj College for Women, Chennai-8. \\ 2. Assistant Professor, Department of Chemistry, A. M. Jain College, Meenambakkam.
}

\section{Manuscript Info}

Manuscript History:

Received: 22 May 2016

Final Accepted: 19 June 2016

Published Online: July 2016

Key words:

Bio-reduction, Ultra sonication, Silver Nano particles, Iron Nano particles, Green Chemistry, SonoChemistry.

*Corresponding Author

............................

S.Kothai

\begin{abstract}
In an attempt to reduce hazardous wastes, a solvent free green route for the synthesis of Silver and Iron Nano particles using the bio-reductantgreen tea extract is reported. The extract is acting both as reducing and capping agent. The bio-reduction process was intensified with ultrasonic waves of frequency of $40 \mathrm{kHz}$. Implosion of microscopic bubbles (Cavities) at the compression phase of the ultrasonic waves produce an ambient condition of temperature and pressure resulting in the easy formation of Silver and Iron nano particles. The initial characterization of the synthesized Silver and Iron nano particles was done by UV-Visible Spectroscopy which showed a characteristic absorption peak at $453 \mathrm{~nm}$ and $265 \mathrm{~nm}$ for Silver and Iron Nano particles respectively. The elemental composition analysis was done by Energy Dispersive X-ray diffraction Technique (EDAX). The active groups involved in the stabilization of the nano particles were analyzed by IR Spectroscopy. The size and morphology of the synthesized nano particles were determined by Scanning Electron Microscopy (SEM). The effect of ultrasound on the reduction reaction rate was assessed and it was found to get enhanced. The synthesized silver nano particles showed potential anti-bacterial activity.
\end{abstract}

Copy Right, IJAR, 2016.. All rights reserved.

\section{Introduction:-}

Nanotechnology has emerged as a state-of-the-art and cutting edge technology with multifarious applications in a wide array of fields. It is a very broad area comprising of nano materials, nano tools, and nano devices. Amongst nano materials, majority of the research has mainly focused on nanoparticles as they are the building blocks of nano materials. Metal nano particles exhibit distinct physical and chemical properties compared to their bulk counterparts due to their small size and large surface area. Silver nano particles have always attracted researchers due to its wide spread application in various fields such as catalysis ${ }^{1}$, sensors ${ }^{2}$, Food industries ${ }^{3}$, agriculture ${ }^{4}$, textile industries ${ }^{5}$ etc., and most importantly in the biomedical field as antibacterial ${ }^{6}$, anti-oxidant ${ }^{7}$, antimicrobial ${ }^{8}$, anticancer agents ${ }^{9}$ etc. Iron is the metal acting as the active site of many important redox enzymes dealing with cellular respiration and with oxidation reduction in plants and animals. Iron also acts a co-factor and structural component of various enzymes. Due to their exceptional supermagnetism and high co-ercivity,Iron nano particles find extensive use in magnetic recording media $^{10}$, sensors ${ }^{11}$, ferro-fluids, and environmental remediation ${ }^{12-16}$. Though various conventional physical and chemical methods like pyrolysis, attrition, sol-gel ${ }^{17}$, hydrothermal ${ }^{18}$, electrochemical methods ${ }^{19}$, chemical reduction $^{20}$, microwave assisted method $^{21}$, were known for the synthesis of metal nano particles, they are not preferred due to various disadvantages involved in it like defective surface formation, low production rate, high cost of manufacturing, large energy requirement etc., and chemical methods of synthesis involve the usage of toxic chemicals, formation of hazardous byproducts which are undesirable for a pollution free environment. Due to the limitation of these methods, research focus has recently shifted towards the development of clean, non-toxic and eco-friendly protocols for nanoparticle synthesis. 
Bio synthesis of nano particles ${ }^{22-26}$, a kind of bottom up approach, is mainly preferred for its cost effectiveness in the large scale production of nano particles of very small size. In the present study, dried leaves of green tea of Darjeeling origin was used to synthesize Silver and Iron nano particles. Along with this, a process intensification technique- Ultrasonication is combined to enhance the rate and homogeneity of the nano particles formation ${ }^{27-30}$.

\section{Materials and Methods:-}

Silver Nitrate,FerrousSulphatehepta hydrate,-purchased from Qualigens, India.

Dried Long leaves of Green tea - Darjeeling origin.

Instrument:-Wensor Digital Ultrsonicator $(40 \mathrm{KHz})$

\section{Extract Preparation:-}

One gram of well dried and powdered green tea was put in to $50 \mathrm{ml}$ of water and boiled for about 15 minutes . The extract was filtered with Whatman No.1filter paper. This aqueous extract was used to synthesize Silver and Iron nano particles.

\section{Resazurin Micro Titre Anti-bacterial Assay - Minimum inhibitory concentration (MIC).}

\section{Preparation of resazurin solution:-}

The resazurin solution was prepared by dissolving $270 \mathrm{mg}$ in $40 \mathrm{~mL}$ of sterile distilled water. A well-dissolved homogenous solution was produced using a vortex mixer.

\section{Procedure:-}

Test was carried out in a 96 well Plates under aseptic conditions. A sterile 96 well plate was labeled. A volume of $100 \mu \mathrm{l}$ of sample (concentration $5 \mathrm{mg}-0.095 \mathrm{mg}$ ) was pipetted out into the first row of the plate. To all other wells 50 $\mu \mathrm{l}$ of nutrient broth was added and serially diluted it. To each well $10 \mu \mathrm{l}$ of resazurin indicator solution was added. $10 \mu \mathrm{l}$ of bacterial suspension was added to each well. Each plate was wrapped loosely with cling film to ensure that bacteria did not become dehydrated. The plate was incubated at $37^{\circ} \mathrm{C}$ for $18-24 \mathrm{~h}$. The colour change was then assessed visually. Any colour changes from purple to pink or colourless were recorded as positive. The lowest concentration at which colour change occurred was taken as the MIC value.

\section{Results and Discussion:-}

Tea is the most widely -consumed beverage in the world. There are three main varieties of tea - green, black and oolong. They differ in the way they are processed. In particular, green tea has many health benefits. It is made of unfermented leaves of Camellia Sinensis. In traditional medicines, green tea was prescribed as a stimulant, a diuretic, an astringent, and as an anti-aging drink. It also helps to regulate blood sugar, promote digestion, decrease cholesterol, lower blood pressure, prevent cardiovascular diseases, reduce obesity and also improves mental health. All these health benefits of green tea is due to the presence of the bio active components present in it such as polyphenols and flavonoids. The main bio active compounds that are present in the extract are given in Table.1. 

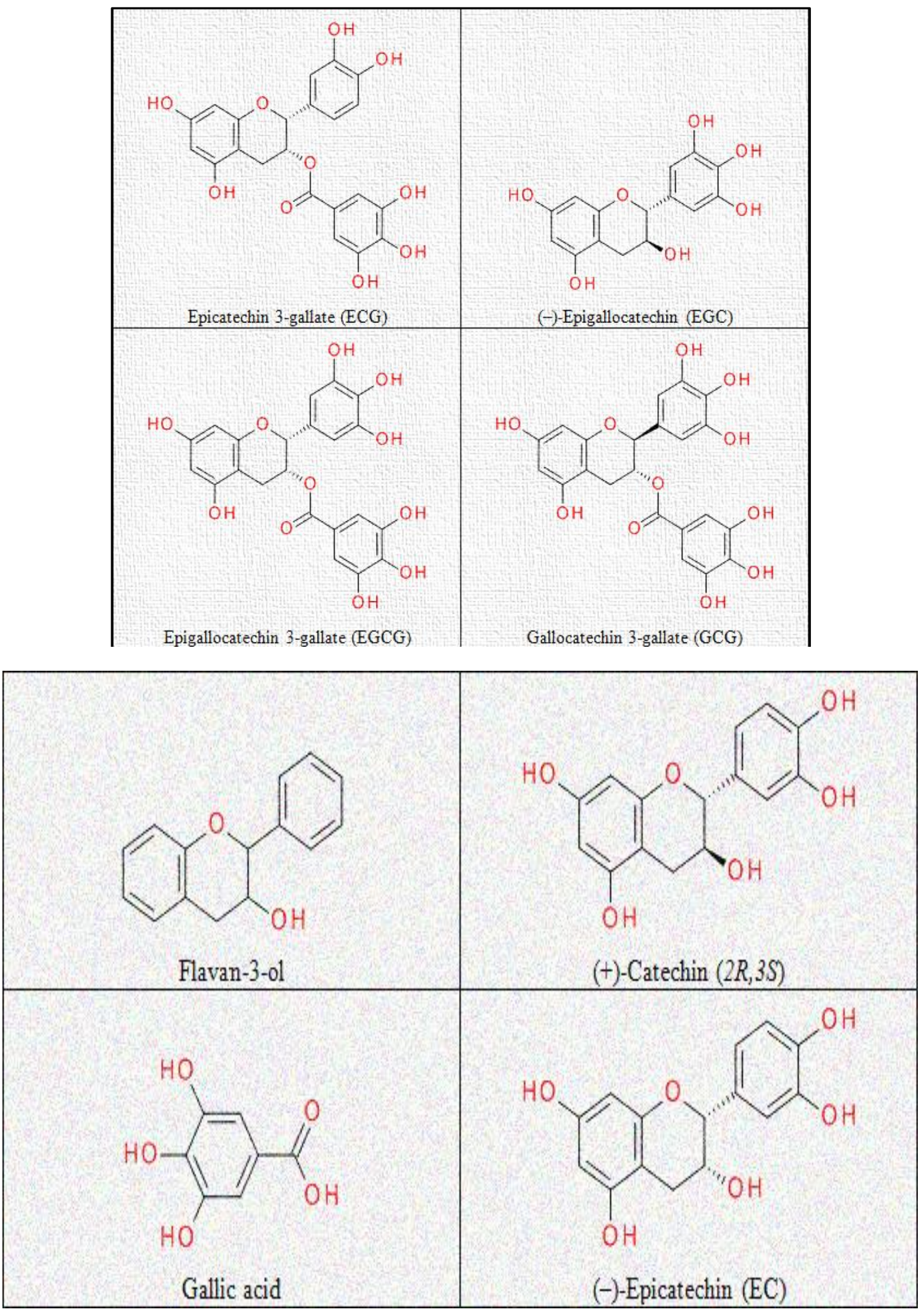

Table-1:-Bio active compounds in Green Tea 


\section{Synthesis:-}

$5 \mathrm{ml}$ of green tea extract was added to $100 \mathrm{ml}$ of $0.001 \mathrm{M}$ Silver nitrate solution. There was a gradual change in colour from pale yellow to reddish brown colour in eight minutes. The appearance of the Reddish brown colour indicated the formation of Silver nano particles. When $5 \mathrm{ml}$ of the extract was added to $100 \mathrm{ml}$ of $0.001 \mathrm{M}$ Ferrous Sulphatehepta hydrate solution, there was a gradual colour change from light yellow to deep blue in twelve minutes. The appearance of blue colour indicated the formation of Iron nano particles. When the same amount of the precursors and the green tea extract were simultaneously irradiated with ultrasonic waves, formation of Silver and Iron nano particles were observed within three minutes and five minutes respectively.

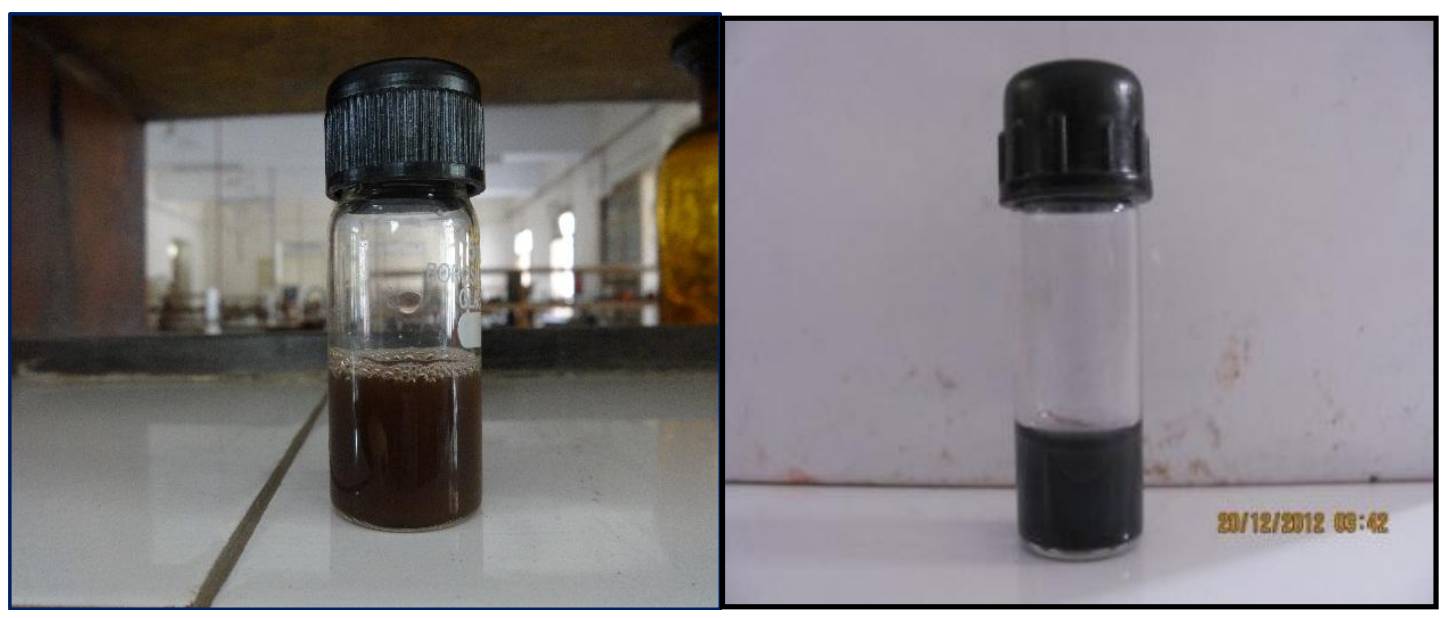

Fig.1A:- Silver nanoparticlesformationFig. 1B. Iron nano particles formation

ECG, EGC, EGCG, GCG, Catechin, Epi-catechin, Gallic acid - bio active ingredients of green tea are all poly phenolic compounds - have strong tendency to donate electron, hence helps in the reduction of silver (1) ions to elemental silver and Ferrous ions to elemental iron.

\section{Mechanism}

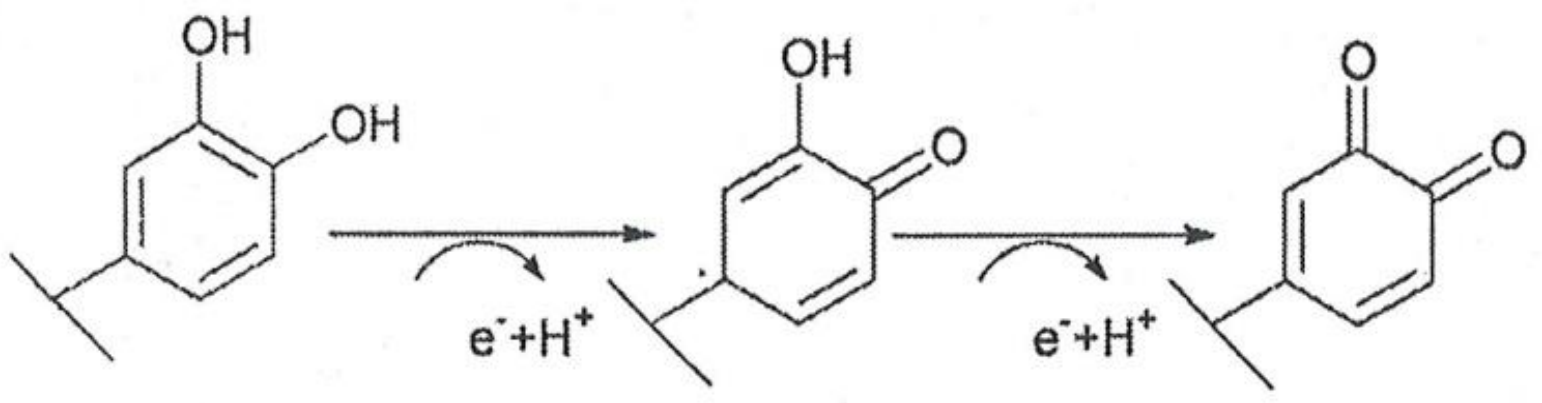

Polyphenols and flavonoids $+\operatorname{Ag}^{+} \rightarrow \operatorname{Ag}(0)$

Polyphenols and flavonoids $+\mathrm{Fe}^{2+} \rightarrow \mathrm{Fe}(\mathbf{0})$ 


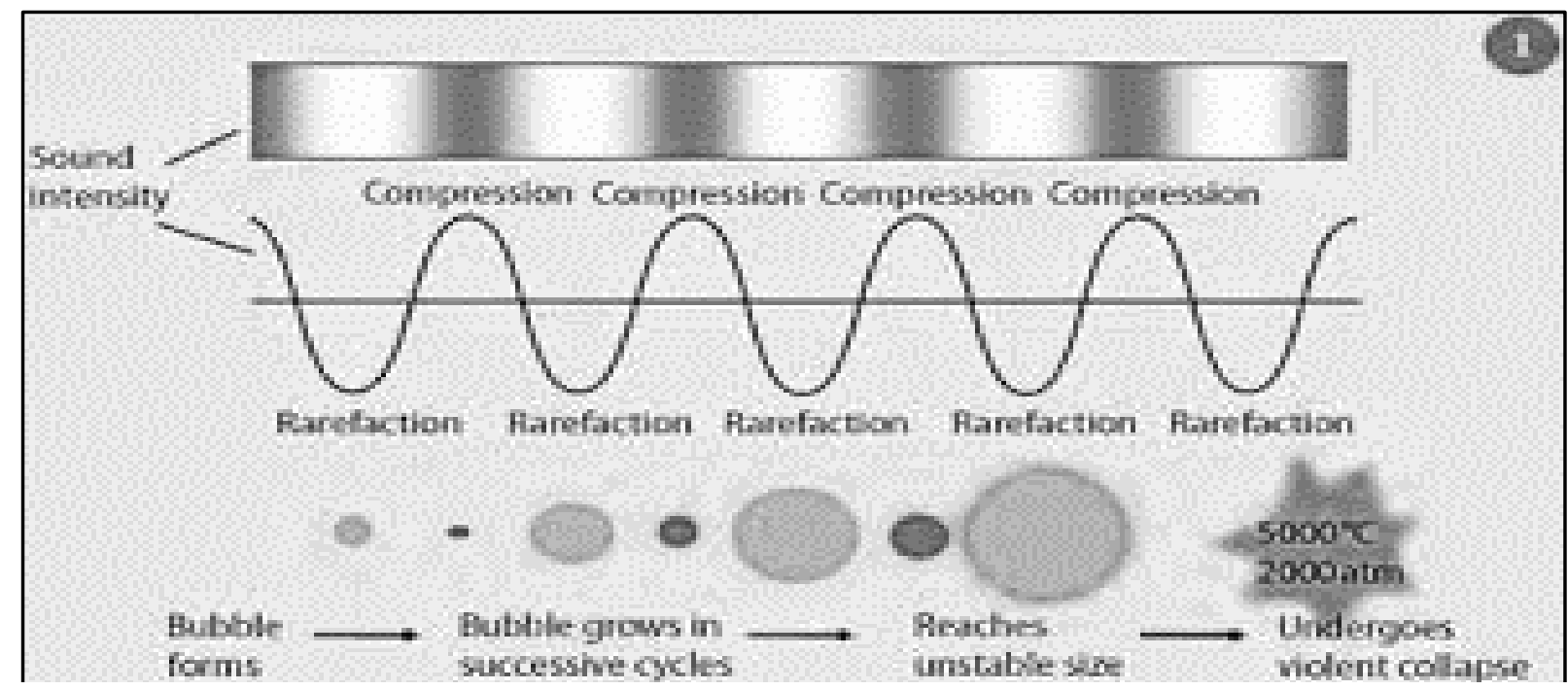

Fig.2:- Formation and collapse of microscopic bubbles during ultrasonication.

During sonolysis, when ultrasonic waves were passed through the reaction mixture, microscopic bubbles called cavities were produced during the decompression phase of the wave and were imploded duing the compression phase. This alternating expansive and compressive acoustic waves make the microscopic bubbles to oscillate ${ }^{27}$.The oscillating bubbles accumulate the ultrasonic energy, grows and implodes when optimum size is reached resulting in the formation of free radicals like H.and OH.as given below ${ }^{(30)}$.

In addition to the active groups responsible for bio- reduction, the free radicals produced during sonolysis of aqueous liquids also involve in the reduction $\mathrm{Ag}^{+}$ions to $\mathrm{Ag}(0)$ and $\mathrm{Fe}^{2+}$ ions to $\mathrm{Fe}(0)$. The mechanism for free radical reduction is

$\mathrm{H}_{2} \mathrm{O} \rightarrow$ H. + OH.

H. + H. $\rightarrow \mathrm{H}_{2}$

H. + OH. $\rightarrow \mathrm{H}_{2} \mathrm{O}$

RH + OH. $\rightarrow$ R. $+\mathrm{H}_{2} \mathrm{O}$

OH. + OH. $\rightarrow \mathrm{H}_{2} \mathrm{O}_{2}$

$\mathrm{Ag}^{+}+$H. $\rightarrow \operatorname{Ag}(0)$

$\mathrm{Fe}^{2+}+2 \mathrm{H} . \rightarrow \mathrm{Fe}(0)$

Sonolysis provides a synergic effect to bio- reduction process that assists in the production of Silver and Iron nano particles of smaller size and with a reasonably faster rate.The synthesized Silver and Iron nano particles were extensively sonicated for about 2 Hours and then characterized.

\section{Characterisation Of Synthesized Nano Particles:[-}

\section{UV-Visible Spectral Analysis:-}

The initial characterization of the synthesized Silver and Iron nano particles was done byShimadzu UV 1650pc Spectrophotometer. The synthesized nano particles were diluted so as to avoid errors due to high optical density. 


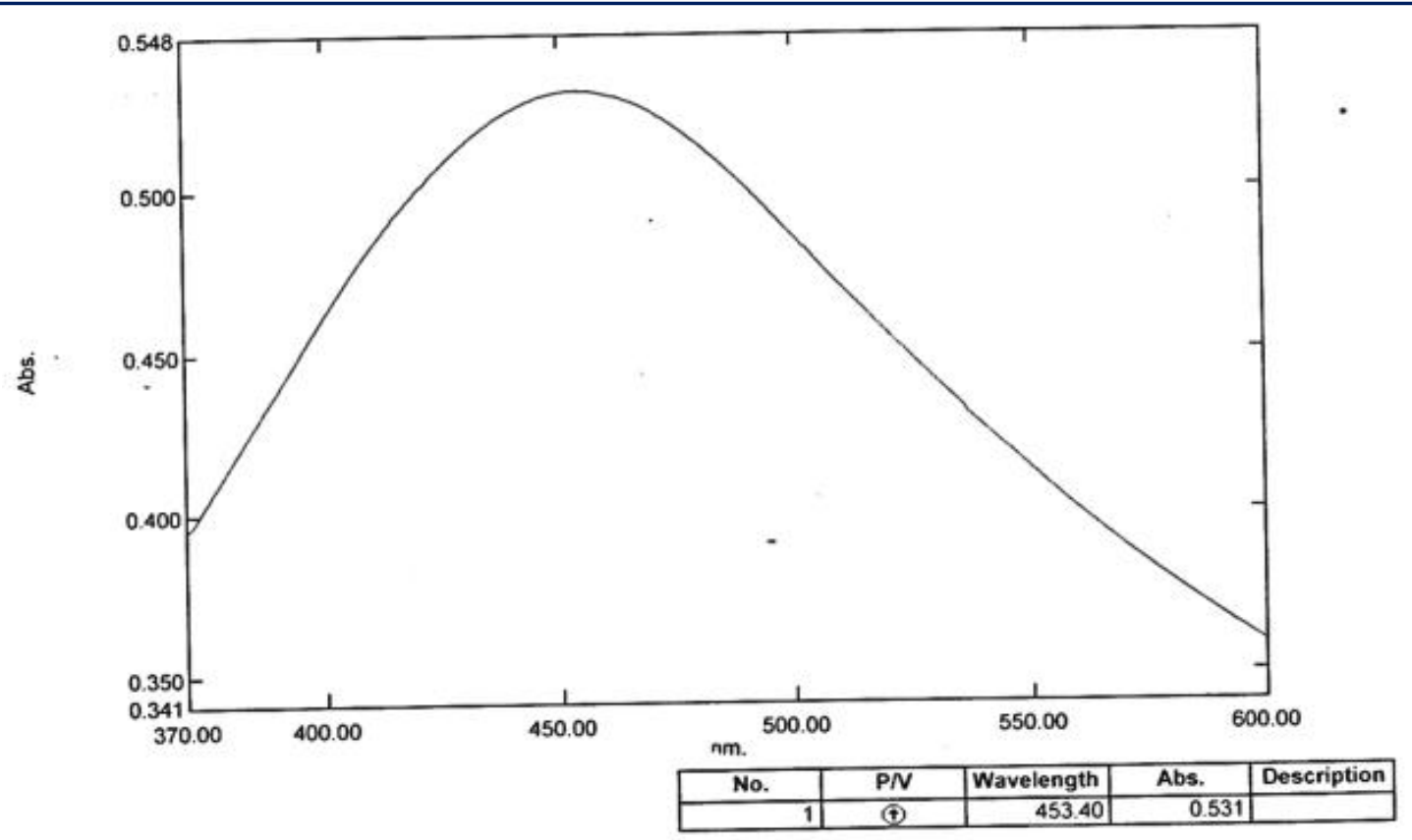

Fig.3A:-UV-Spectrum ofSilver Nano particles

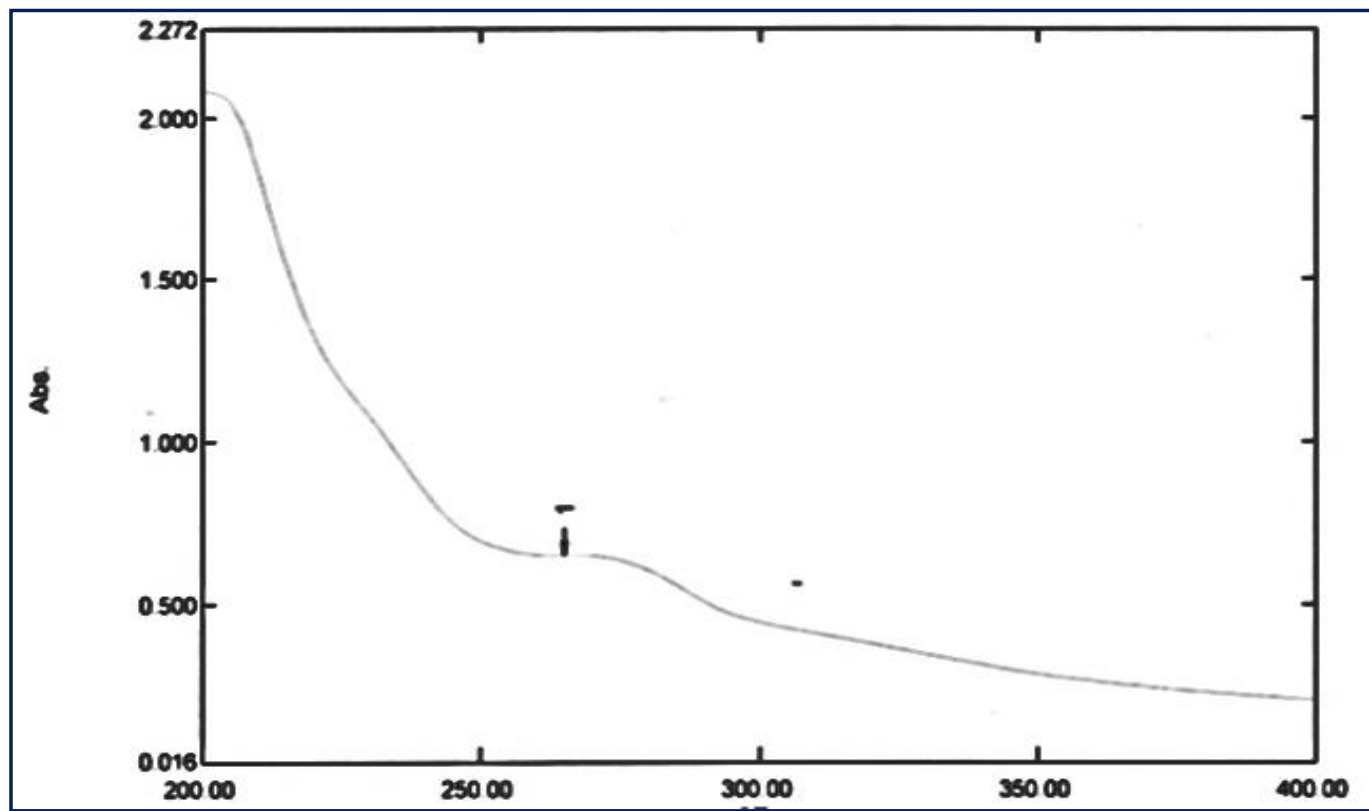

Fig. 3B:-UV Spectrum of Iron Nano Particles

The appearance of surface plasmon resonance peaks at $453 \mathrm{~nm}$ and $265 \mathrm{~nm}$, which is due to the combined effect of vibrations of the free electrons of the synthesized metal nano particles in resonance with the light waves, is characteristic for Silver and Iron nano particles. Thus, UV -Vis spectral analysis provided evidence for the formation of Silver and Iron particles.

\section{Fourier Transform Infra-Red Spctroscopic Analysis:-}

The synthesized Silver and Iron nano particles were centrifuged at 10,000rpm for 15 minutes. Samples are dried and grinded with $\mathrm{KBr}$ pellets for FTIR measurement.

Instrument: Shimadzu FTIR spectrophotometer.

Spectrum Range: Spectrum was recorded in the range of $4000-400 \mathrm{~cm}^{-1}$. 


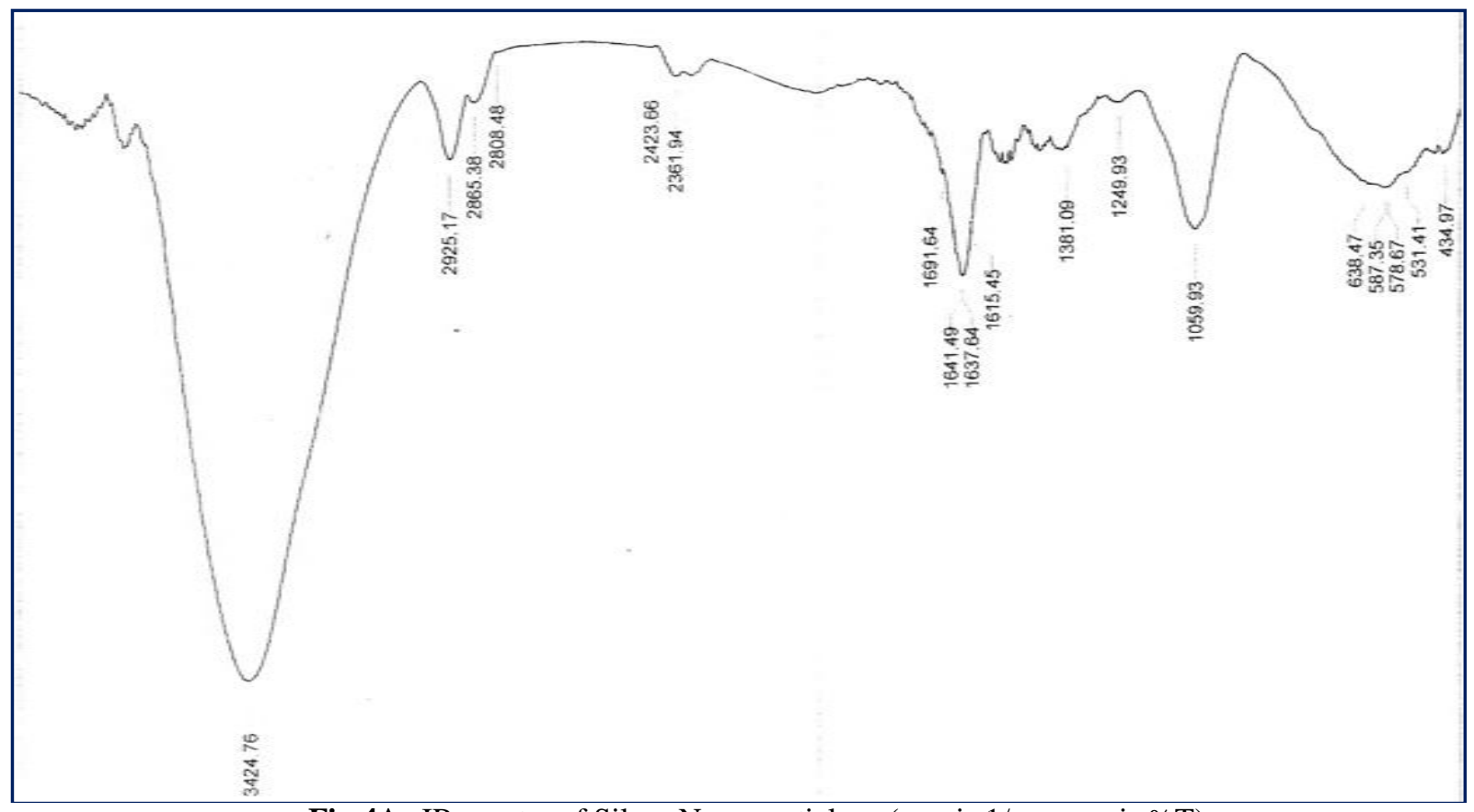

Fig.4A:-IR spectra of Silver Nano particles $\quad(\mathrm{x}$-axis $1 / \mathrm{cm}$, y axis \%T)

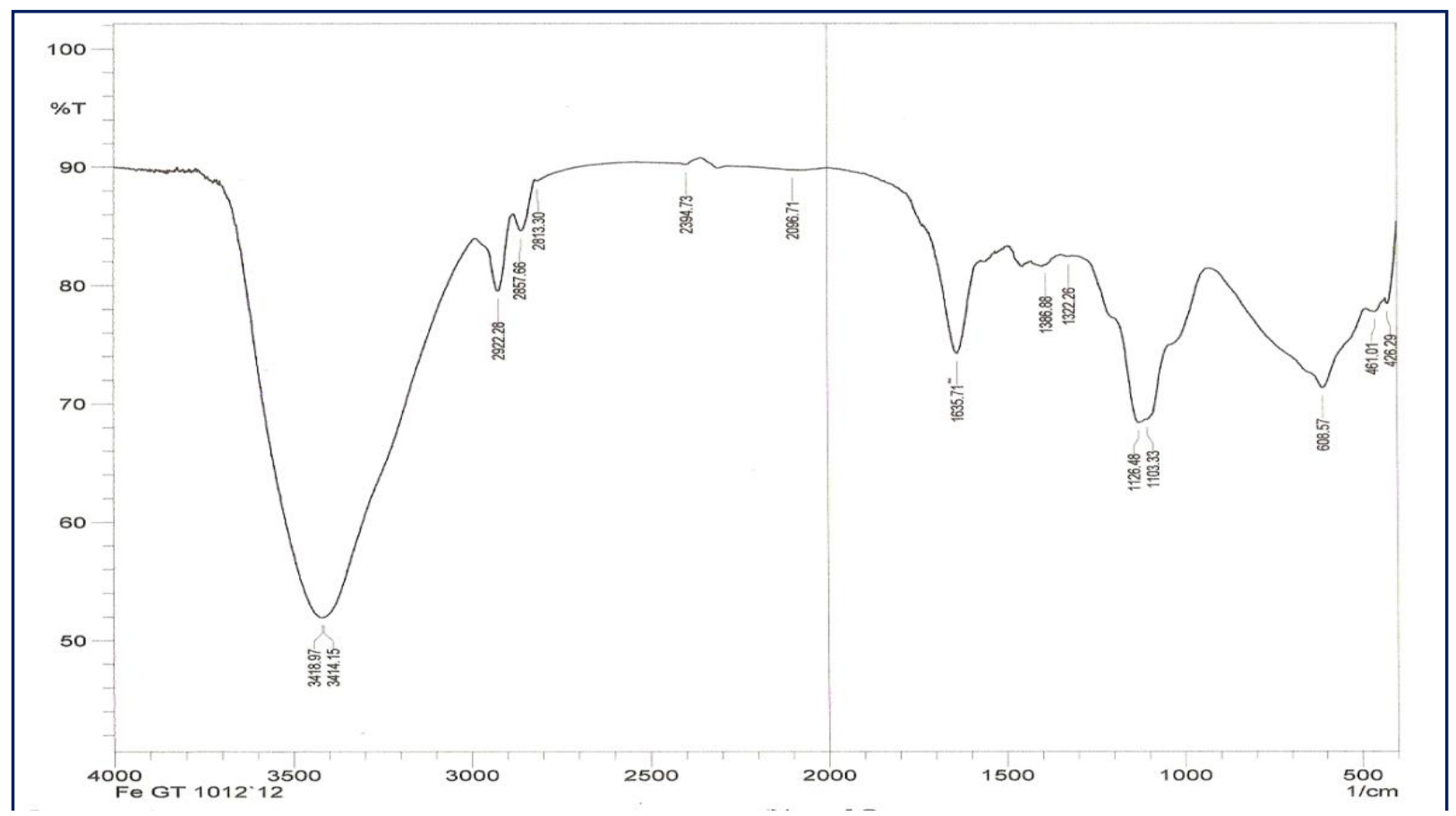

Fig. 4B:-IRspectra of Iron NanoParticles

Analysis of FT-IR spectra of both Silver and Iron nano particles showed a broad absorption peak at $3424 \mathrm{~cm}^{-1}$ and at $3418 \mathrm{~cm}^{-1}$ respectively which corresponds to O-H stretching frequency. A peak at $2925 \mathrm{~cm}^{-1}$ and $2922 \mathrm{~cm}^{-1}$ in both the spectra corresponds to that of N-H and cycloalkanic C-H stretching mode of vibrations. Peaks at $2885 \mathrm{~cm}^{-}$ ${ }^{1}, 2808 \mathrm{~cm}^{-1}$ in Silver nano particle spectrum and peaks at $2857 \mathrm{~cm}^{-1}$ in Iron nano particle spectrum corresponds to that of hydroxyl group of carboxylic acid and aliphatic $\mathrm{C}-\mathrm{H}$ stretching frequency mode. These prominent peaks showed the presence of polyphenolic groups. A peak at $1637 \mathrm{~cm}^{-1}$ in Silver nano spectra and peak at $1635 \mathrm{~cm}^{-1}$ in Iron nano spectra corresponds to that acid $\mathrm{C}=\mathrm{O}$ group .A peak at $1381 \mathrm{~cm}^{-1}$ and peaks at $1386 \mathrm{~cm}^{-1}, 1322 \mathrm{~cm}^{-}$ ${ }^{1}$ corresponds to that of $\mathrm{C}=\mathrm{O}$ of ester group. Peaks at $1240 \mathrm{~cm}^{-1}$ and at $1059 \mathrm{~cm}^{-1}$ in silver nano spectra corresponds 
to some amines in the extract. So it can be assumed that the water soluble alkaloids, flavonoids and phenols present in the extract are acting as both reducing agent as well as stabilizing agent.

\section{Energy Dispersive X-Ray Analysis (EDAX):-}

Instrument: Drop coatednano particle samples were examinedunder Philips XL-30.

The presence of specific elements present in the sample were determined by the EDAX attachment on the Scanning Electron Microscope.EDAX spectrum of Silver nano particles sample was given in Fig.5A and EDAX spectrum of Iron nano particles sample is given in Fig.5B.

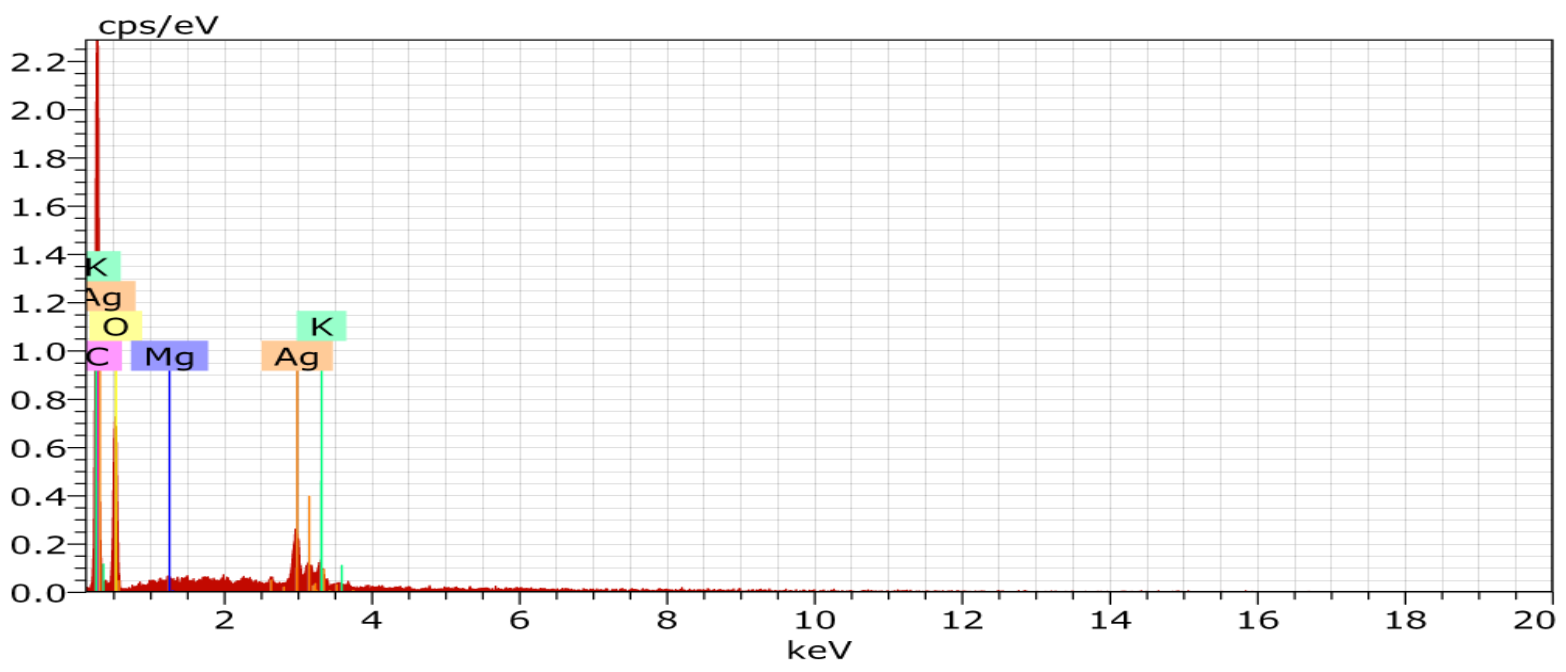

Fig. 5A:- EDAX of Silver Nano particles

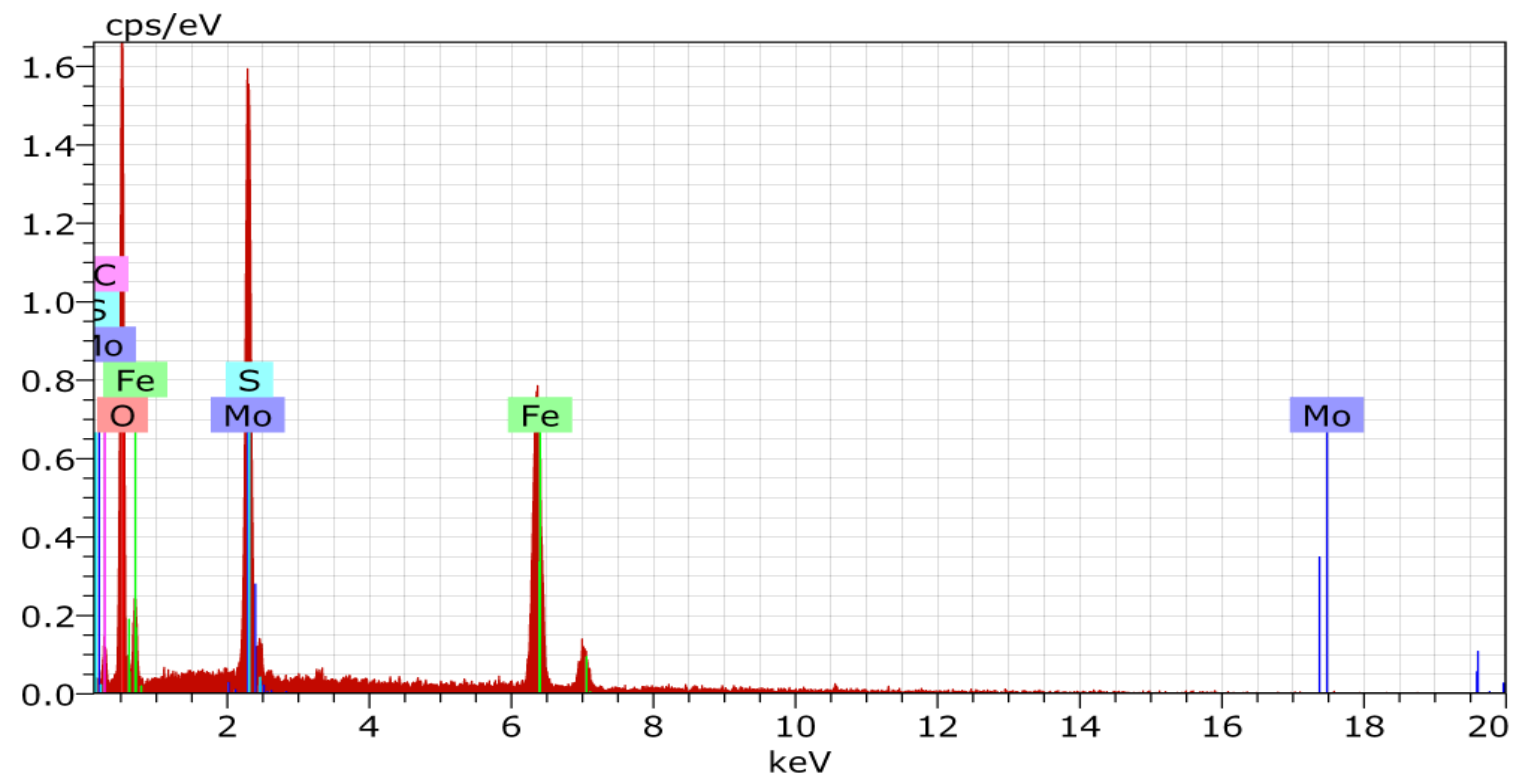

Fig. 5B:- EDAX of Iron Nano particles

In Figure 5A, an optical absorption peak is observedat $3 \mathrm{KeV}$ which is typical for the absorption of metallic Silver nano particles. Optical absorption peak at $6.25 \mathrm{KeV}$ in Figure $5 \mathrm{~B}$ is characteristic for absorption of metallic Iron nano particles. These characteristic optical absorption peaks confirmed the formation of metallic Silver and Iron nano particles. 


\section{Scanning Electron Microscopicanalysis:-}

\section{Sample:-}

Thin film of the sample was prepared on a carbon coated grid by dropping a very small amount ofthe sample on the grid. The sample film was dried by exposing it under mercury lamp. SEM images of the synthesized Silver and Iron nanoparticles at different magnifications were given in Figure 6A and Figure 6B.

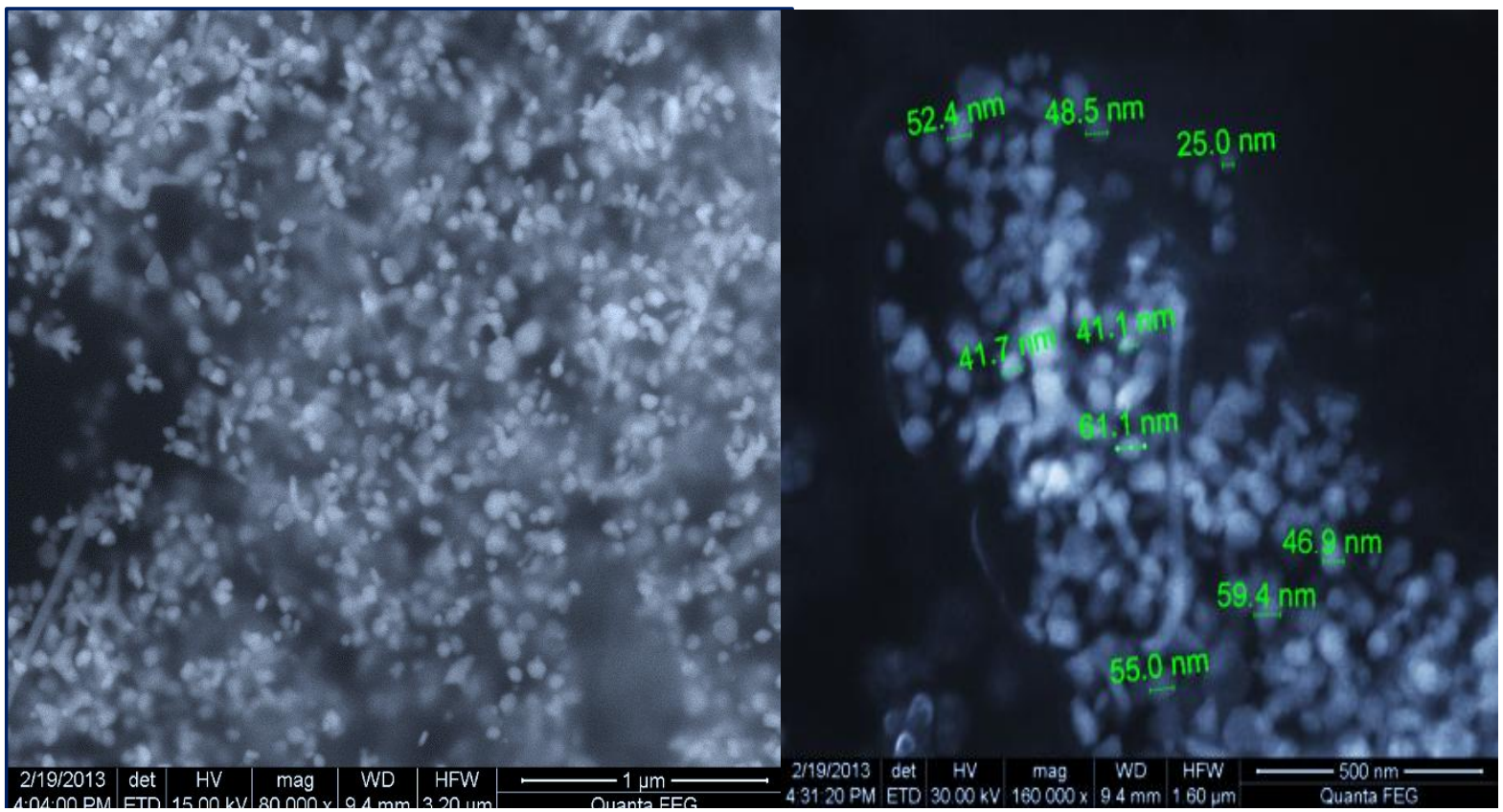

Fig. 6A:-SEM images of Silver Nano particles

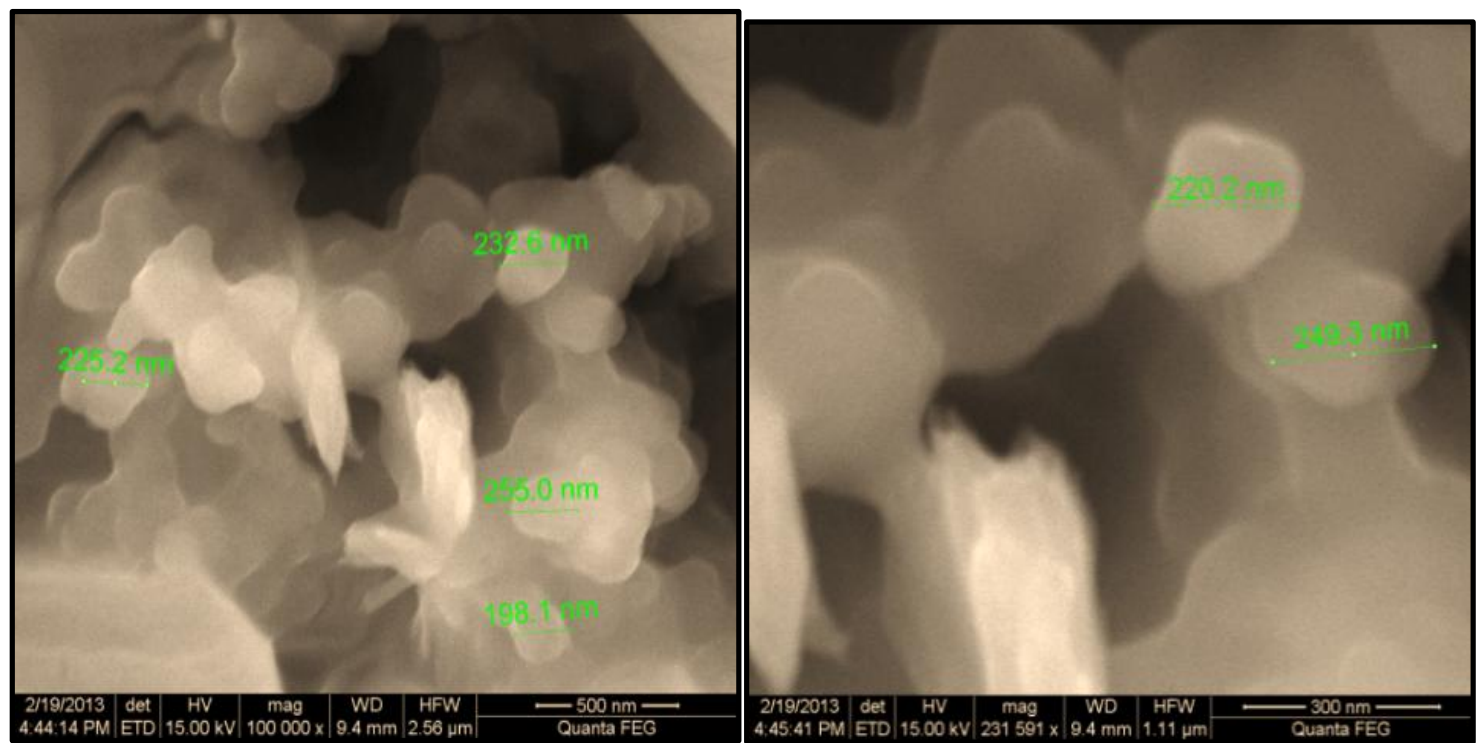

Fig. 6B:-SEM images of Ironnano particles

SEM images of the synthesized silver nano particles reveal that the particles are predominantly spherical in shape and the average particle size is $47 \mathrm{~nm}$.SEM images of synthesized Iron nano particles at different magnifications showed that the particles have sheet-like structures and the size of the particles are comparatively bigger than desired size, that may be due to thin coating of bio-molecules of the extract on the nano particles. 


\section{Anti-bacterial Activity Of Silver Nano Particles:-}

Silver nano particles due to its smaller size and high surface charge, attaches itself potentially to the cell membranes of bacteria, penetrates and causes structural alterations in the proteins leading to microorganism destruction.This activity depends on the size and shape of the Silver nano particles synthesized. The anti-bacterial activity of the biosonochemically synthesized Silver nano particles was tested on a Gram negative - E. coli and a Gram positive bacteria - Staphylococcus aureus by resazurinmicrotitre method and the results are given inTable 2.The synthesized Silver nano particles showed very good antibacterial activity against the tested microorganisms. The Minimum inhibitory concentration values are given in Table 3.

Table 2:-Antibacterial activity of the synthesized silver nano particles

\begin{tabular}{|l|l|l|l|l|l|l|l|l|l|l|l|}
\hline Microorganism & \multicolumn{10}{|l|}{ Growth of inhibition } \\
& $\begin{array}{l}10 \\
\mathrm{mg}\end{array}$ & $\begin{array}{l}5 \\
\mathrm{mg}\end{array}$ & $\begin{array}{l}2.5 \\
\mathrm{mg}\end{array}$ & $1.25 \mathrm{mg}$ & $\begin{array}{l}0.625 \\
\mathrm{mg}\end{array}$ & $\begin{array}{l}0.312 \\
\mathrm{mg}\end{array}$ & $\begin{array}{l}0.156 \\
\mathrm{mg}\end{array}$ & $\begin{array}{l}0.078 \\
\mathrm{mg}\end{array}$ & $\begin{array}{l}\text { Std } \\
10 \mu \mathrm{g}\end{array}$ & $\begin{array}{l}\text { DMSO } \\
(-\mathrm{ve} \\
\text { control) }\end{array}$ & $\begin{array}{l}\text { Postive } \\
\text { Control } \\
\text { (culture) }\end{array}$ \\
\hline E. Coli & - & - & - & + & + & + & + & + & - & + & + \\
\hline $\begin{array}{l}\text { Staphylococcus } \\
\text { aureus }\end{array}$ & - & - & - & - & + & + & + & + & - & + & + \\
\hline
\end{tabular}

Table.3:-Minimum inhibitory concentration against Micro organisms

\begin{tabular}{|l|l|}
\hline Microorganisms & \multicolumn{1}{|c|}{ MIC Value } \\
\hline E. coli $($ gram - ve) & $2.5 \mathrm{mg}$ \\
\hline Staphylococcus aureus (gram +ve) & $1.25 \mathrm{mg}$ \\
\hline
\end{tabular}

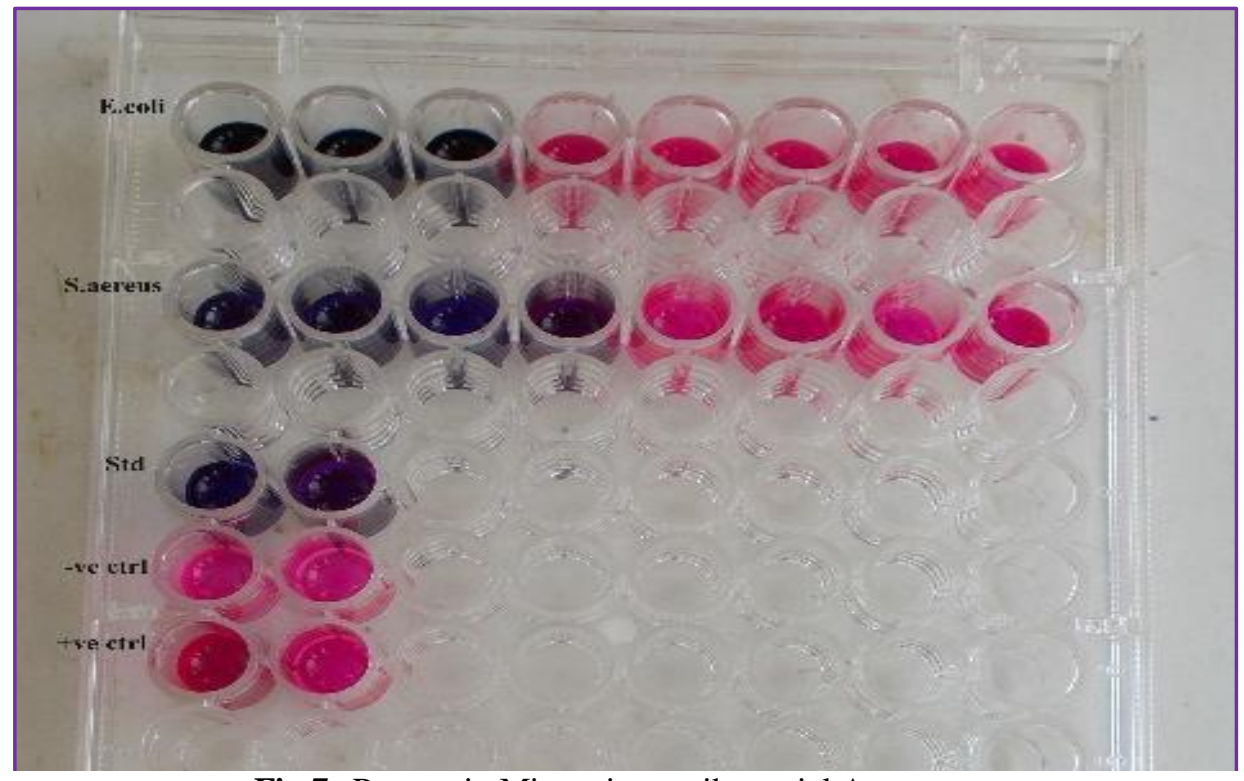

Fig 7:-Resazurin Micro-titre antibacterial Assay

From MIC value, it was found that it could inhibit the gram positive bacteria,Staphylococcusaureus $(1.25 \mathrm{mg})$ better than the gram negative bacteriaE. coli $(2.5 \mathrm{mg})$.

\section{Conclusion:-}

This method of synthesis of silver and iron nano particles, is a clean and quick method which combines the advantages of both Green Chemistry and Sono Chemistry. The synthesized sphericalSilver nano particles of average size $47 \mathrm{~nm}$ - exhibited very good antibacterial activity. The synthesized Iron nano particles have sheet like structure. This procedure has several advantages such as cost effectiveness, compatibility for medical and pharmaceutical applications as well as for large scale production. 


\section{References:-}

1. State of the Science- Literature Review: (2010) "Everything Nanosilver and more." Environmental Protection Agency, USA.

2. Ren X, Meng X, Chen D, Tang F, Jiao. (2005). “Amperometric glucose biosensor based on a triangular silver nano prisms/chitosan composite film as immobilization matrix".J.Biosens. Bioelectron. 21,433-437.

3. Chaudhry Q, Castle L. (2011). "Food applications of nanotechnologies: an over view of opportunities and challengs for developing countries".Trends Food Sci Tech, 22,595-603.

4. Nair R, Varghese SH, Nair BG, Maekawa T, Yoshica Y, SakthiKumarD. (2010). "Nan particulate material delivery to plants". Plant sci, 179, 154-163.

5. Kelly FM, Johnson JH. (2011). "Colored and functional silver nano particles wool fiber composites". ACS appl. Mater interfaces 3, 1083-1092.

6. Nair LS, Laurencin C.T. (2007). "Silvernano particles: Synthesis and therapeutic applications." J. Bio med Nano technol. 3,301-316.

7. Niraimathi KL, Sudha V. Lavanya R, Brindha, P. (2013). "Biosynthesis of silver nano particles using Alternantherasessils extract and their antimicrobial, antioxidant acitvities". Colloid Surface B. 102, 288-291.

8. Sondi.I, Salopek-Sondi. (2004). "Silver nanoparticles as antimicrobial agent: A case study on E.Coli as a model for Gramnegative bacteria." J.Colloid Interface Sci , 275, 177-182.

9. Gopinath, SK. Gogoi, P. Sanpui A. Paul A. Chattopadhyay, S.S.Ghosh, (2010) "Signaling gene cascade in silver nano particle induced apoptosis," Colloids and surfaces B, 77, no.2.240-245.

10. Sun S, Murray CB.Weller D. Folks L. Moser A. (2000) "MonodisperseFePt nanoparticles and ferromagnetic FePtnanocrystalsuperlattices"Science. 287, 1989-1991.

11. C.Jianrong, M. Yuqing, H. Nongyue, W.Xiaohua, L.Sijjiao, (2004) "Nanotechnology and biosensors". Biotechnol Adv. 22,505 .

12. Kanel S, Manning, B, Charlet L, Choi, H. (2005) "Removal of arsenic (III) from groundwater by nanoscale zerovalentiron".Environ. Sci. Technol. 39, 1291-1298.

13. Cao J. Elliott, D. Zhang W. (2005) "Perchlorate reduction by nanoscale iron particles". J. Nanopart. Res. 7, $499-506$.

14. Chen S, Hsu H, Li C. (2004) "Hexavalent chromium removal from water using chitosan- Fe (0) Nanoparticles". J.Nanopart. Res. 6, 639-647.

15. Gillham RW, Hannesin SF. (1994)“Enhanced degradation of halogenated aliphatics by zero-valent iron". Ground Water. 36, 958-967.

16. Wang, CB. Zhang, WX. (1997). "Synthesizing nanoscale iron particles for rapid and complete dechlorination of TCE and PCBs". Environ. Sci. Technol. 31, 2154-2156.

17. M.Epifani, C.Giannini, L.Tapfer, L.Vasanelli. (2000). "Sol-gel synthesis and characterization of Ag and Au nanoparticles in $\mathrm{SiO} 2, \mathrm{TiO} 2$, and $\mathrm{ZrO} 2$ thin films". Journal of the American Ceramic Society. 83, 2385.

18. Z.Yang, H.Qian, H.Chen, JN. Anker.(2010). "One-pot hydrothermal synthesis of silver nanowires via citrate reduction".J Colloid Interface Sci, 352 (2), 285.

19. Yu YY, Chang SS, Lee CL, Wang CRC. (1997) "Goldnanorods: electrochemical synthesis and optical properties". J. Phys. Chem. Biotecnol.101, 6661-6664.

20. T.Hyeon, (2003). "Chemical synthesis of magnetic nano particle" Chemical Communications Vol. 9, no.8, pp 927-934.

21. Binghui Wang, XupinZhuang, Wenjian Deng, Bowen Cheng. (2010) "Microwave-Assisted Synthesis of Silver Nanoparticles in AlkalicCarboxymethyl Chitosan Solution".Scientific research.Vol.2 no. 5397-400.

22. SandeepDhuper, Darshan Panda, P. L. Nayak. (2012) "Green Synthesis and Characterization of Zero Valent Iron Nanoparticles from the Leaf Extract of Mangiferaindica". Nano Trends: A Journal of Nanotechnology and Its Applications. $3,(2), 16$.

23. Njagi E.C, Huang H, Stafford L. et al ( 2011) " Biosynthesis of iron and silver nano particles at room Temperature using aqueous Sorghum bram extracts" Langmuir. 27, (1), 264-271.

24. Wang T, JinX, Chen Z, Megharaj M and Naidu R. (2014) "Green synthesis of Iron nano particles using eucalyptus leaf extracts for treatment of eutrophia waste water" Science of the Total environment. 210-213.

25. Shankar S.S, Ahmad A. Sastry M. (2003) "Geranium leaf assisted biosynthesis of silver nanoparticles". Biotechnology progress.19, (6), 627-163.

26. Chandran SP, Chaudhary M, Pasricha R, Ahmad A, Sastry M. (2006)"Synthesis of gold nanotriangles and silver nanoparticles using Aloe vera plant extract," Biotechnology progress, .22 ( 2),577-583.

27. Gendaken A. (2003) "Sonoochemistry and its application to nanochemistry", Current Science. 85 (12), 1720-1722.

28. VimalKumar,KrishnaDeo Prasad Nigam.(2012)"Process intensification in green synthesis", Green process synth. 1,79-107.

29. Kumar R.V. (2002) "Sonochemical synthesis and characterization of $\mathrm{Ag}_{2} \mathrm{~S} / \mathrm{PVA}$ and CuS/PVA nano composite",UltrasonicsSonochemistry. 9, 65-70.

30. Jin Ho Bang, Kenneth,S. Suslick.(2010) "Applications of Ultrasound to the synthesis of Nanostructured Materials".Advanced materials..22,1039-1059. 